\title{
USOS POTENCIAIS DA TERRA NA ANTIGUIDADE COMO ALTERNA- TIVA ÀS REPRESENTAÇÕES CARTOGRÁFICAS DOS SOLOS EXIS- TENTES EM PORTUGAL. O CASO DA CIVITAS IGAEDITANORUM (IDANHA-A-VELHA, PORTUGAL)
}

\author{
SOFIA LACERDA ${ }^{(1)}$
}

Resumo:

\begin{abstract}
Os Mapas de Uso Potencial da Terra são representações cartográficas que nos permitem refletir sobre os usos prováveis da terra na antiguidade. Não se devem confundir com a cartografia tradicional de solos, uma vez que, ao contrário desta, os Mapas de Uso Potencial da Terra são criados de forma a conter um valor histórico. Embora este tipo de cartografia permita a criação de diferentes cenários produtivos, enquadrados num determinado período, não significa que seja representativo da realidade, mas sim de uma possibilidade. Neste artigo apresentamos o caso concreto do Mapa de Usos Potenciais da Terra criado para parte do território da civitas Igaeditanorum (Idanha-aVelha, Portugal).

Ao mesmo tempo que pretendemos encorajar a criação e uso deste tipo de cartografia, consideramos importante mostrar os perigos que incorremos ao utilizarmos na investigação arqueológica a cartografia de solos atualmente
\end{abstract} disponível em Portugal.

Palavras-chave: SIG, Cartografia, Paisagem Rural, Arqueologia Agrária.

\begin{abstract}
:
Land evaluation in antiquity as an alternative to Portuguese soil representation. The case of civitas Igaeditanorum (Idanha-a-Velha, Portugal)

Potential Land Use Maps are cartographic representations that allow us to think about the most probable land uses in the past. These maps shouldn't be mistaken with the traditional soil cartography since those are created from an historical prespective. Although this kind of cartography allows the creation of different exploitation scenarios, integrated on a specific historical period, it should not be taken as a representative reality, but as a possibility. In this paper we present the case of civitas Igaeditanorum (Idanha-a-Velha, Portugal) Potential Land Use Map.

At the same time, we intend to encourage the creation and use of these maps, as well as warn about the flaws that exist
\end{abstract} when we apply the traditional soil cartography available in Portugal.

Keywords: GIS, Cartography, Rural Landscape, Agrarian Archaeology.

\section{CARTOGRAFIA PORTUGUESA DE SOLOS E A SUA INADEQUADA APLICA- ÇÃO NA ARQUEOLOGIA}

A consulta de cartografia temática na investigação arqueológica é prática regular. O problema é quando se ignora a lógica funcional que está por trás desses mapas e, consequentemente, se cometem erros ao estabelecer interpretações arqueológicas com base nos mesmos. Desta forma, importa conhecer com clareza qual a informação que nos é transmitida por cada um dos mapas atuais que representam o solo português e o quão desajustada está relativamente ao passado.

Os solos portugueses encontram-se representados a partir de diferentes enfoques: edafológico, de classes agronómicas, de uso e ocupação atual e especificamente de uso agrícola e florestal, além da RAN (Reserva Agrícola Nacional) e da REN
(Reserva Ecológica Nacional). Atualmente, em Portugal, estas representações comportam problemas diversos e encontram-se desatualizadas. No que respeita à sua utilização no âmbito da investigação arqueológica, encontramos um uso predominante de mapas edafológicos e de classes agronómicas, e um uso escasso ou mesmo nulo dos restantes tipos.

\subsection{Cartas de solos de Portugal}

As Cartas de Solos de Portugal classificam os solos e mostram a sua distribuição espacial. Nestes mapas, a classificação dos solos tem em consideração aspetos fundamentalmente científicos inerentes ao próprio solo, destacando-se a diversidade de substratos rochosos na medida em que estes influenciam significativamente a meteorização e a

${ }^{(1)}$ Mestre em Arqueologia e Território pela Faculdade de Letras da Universidade de Coimbra. Contacto: a.sofialacerda@hotmail.com. 
pedogénese, mas também a morfologia do relevo ou as variações climáticas (PISSARRA, 1980-1981: 261).

Em Portugal, a produção de cartografia de solos teve início na segunda metade do século passado a propósito do Plano de Fomento Agrário promovido pelo Secretário de Estado da Agricultura, ficando nos anos seguintes a cargo do SROA (Serviço de Reconhecimento e Ordenamento Agrário). Neste âmbito salientam-se as Cartas de Solos que cobrem a maior parte do país, baseadas na classificação de Carvalho Cardoso (1965; 1974): produziram-se 81 cartas à escala 1: 50000 que abrangem a região a sul do Tejo, parte do Ribatejo e Centro e uma pequena área do Nordeste de Portugal; para as regiões Centro, Ribatejo e Oeste existem Cartas não publicadas cuja classificação também deverá ser a portuguesa, a incerteza resulta da ausência de referências à metodologia utilizada (S.P.C.S., 2004: 4; 21-24). As Cartas Complementares do Solo, são uma produção do SROA / CNROA / IEADR / IHERA / IDRHa / DGADR e apresentam uma escala 1: 25000.

A propósito dos consórcios Agroconsultores e Coba (1991) e mais tarde Agroconsultores e Geometral $(1995$; 1999), produziram-se, para Trás-osMontes e Alto Douro, Entre Douro e Minho e região Interior Centro, cartas à escala 1: 100000 de acordo com o sistema taxonómico da FAO (Food and Agriculture Organization of the United Nations) nas duas primeiras regiões e de acordo com a sistematização da WRB (World Reference Base for Soil Resources) para o Interior Centro. Nas áreas de interesse agrícola do Entre Douro e Minho desenvolveu-se também uma Carta de Solos à escala 1: 25 000. (S.P.C.S., 2004: 10-21).

Desde o ponto de vista arqueológico, os dados contidos nestes mapas têm sido utilizados para fins meramente descritivos do entorno dos sítios. Raramente esta informação é integrada de forma a produzir ilações sobre os sítios arqueológicos.

As descrições exaustivas do entorno, não só dos solos, mas também da litologia, da vegetação, etc., são prática recorrente em Arqueologia, mas não têm utilidade quando desarticuladas com os sítios arqueológicos: de que nos serve descrever detalhadamente os solos que estão no entorno de um sítio, se não conseguimos perceber de que forma essa variedade de solos interessa no âmbito dos sítios que estamos a estudar? Estes relatos sem articulação com os dados arqueológicos acontecem porque não se conhece exatamente o potencial associado aos diferentes tipos de solos e, portanto, como utilizar essa informação. Mas também podem dever-se ao facto de nem sempre conhecermos suficientemente os próprios sítios de forma a compreender o aproveitamento que poderá ter sido feito dos solos. A verdade é que esta prática descritiva parece ter-se cristalizado como mote obrigató- rio nos trabalhos de arqueologia, sendo na maior parte dos casos dispensável.

Normalmente, a ponderação do fator solo relaciona-se com atividades de carácter agrícola. Porém, como veremos mais à frente, considerar exclusivamente o solo para avaliar a maior ou menor aptidão agrícola é um erro. A avaliação da aptidão agrícola dos sítios deve considerar o solo (tipo, profundidade), mas também os vários aspetos do território (relevo, afloramentos rochosos) ou do clima (temperatura, regime hídrico, risco de geada).

\subsection{Cartas de capacidade de uso do solo de Portugal}

As Cartas de Capacidade de Uso do Solo (CCU) são um tipo de cartografia que, tendo como referência as Cartas de Solos, interpretam e avaliam a aptidão dos mesmos. Estes mapas agrupam os solos em classes e subclasses agrológicas que avaliam a capacidade de uso em função das suas limitações. As classes estipulam o grau da limitação do solo num mecanismo de avaliação decrescente de "A" a "E", onde "A" pressupõe limitações mínimas e "E" limitações máximas. Por seu turno, as subclasses indicam qual a limitação dominante: "e" - erosão e escoamento superficial; "h" - excesso de água; e "s" - limitações no solo na zona radicular.

Nestas cartas, a noção de limitação está estritamente ligada com a capacidade de utilização do solo. Essa utilização mudou desde o momento em que esta cartografia foi produzida até aos dias de hoje, e ainda mais desde o passado até à atualidade. Logo aqui entendemos a gravidade da aplicação desta cartografia ao passado: é que o contexto económico, tecnológico e agrícola que formata a utilização do solo sofreu alterações demasiado significativas de período para período. Esta situação pode levar a que seja dada como garantida a classificação de uma determinada zona como tendo uma elevada aptidão agrícola, quando se encarada por exemplo à luz do Período Romano, se trata de uma zona de baixa aptidão agrícola.

Outra questão é o facto de apenas se considerar o solo no processo de avaliação agrícola. A Organização das Nações Unidas para a Alimentação e Agricultura tem trabalhado na solução desta imprecisão, propondo uma metodologia que considera as múltiplas variáveis da terra e não apenas o solo: "[...] land as an area of the earth's surface, the characteristics of which embrace all reasonably stable, or predictably cyclic, attributes of the biosphere vertically above and below this area, including those of the atmosphere, the soil and underlying geology, the hydrology, the plant and animal populations, and the results of past and present human activity, to the extent that these 
attributes exert a significant influence on present and future uses of the land by humans." (FAO, 2007).

A aplicação desta cartografia na arqueologia portuguesa é muito frequente e, em muitos casos, prescindível. Por um lado, são muitas as situações onde nada acrescenta aos trabalhos desenvolvidos porque figura, tal como as Cartas de Solos, como um "elemento decorativo", concretizandose em longas descrições. Por outro lado, quando tentamos integrar esta informação com os dados arqueológicos sujeitamo-nos a erros interpretativos, pois em pouco se assemelha o contexto para o qual estes mapas foram produzidos e o contexto tecnológico por exemplo da Proto-História. Uma avaliação de aptidão agrícola aplicada à ProtoHistória não poderia, por exemplo, considerar solos pesados como tendo uma aptidão ótima, pois não existia tecnologia para os trabalhar. Mesmo no Período Romano, onde o arado mais eficaz que se conhece é o "arado de aivecas" (ALARCÃO, 2004: 29-39), dificilmente se trabalhavam estes solos.

Um artigo de Victor S. Gonçalves, nos finais do século passado, dá-nos conta da posição da geógrafa Suzanne Daveau a propósito da aplicação desta cartografia na Arqueologia, mais concretamente na Pré-História: "Longamente discuti com Suzanne, que resistia à ideia de se apresentarem para a Pré-História mapas de capacidade de uso dos solos, e esse foi dos poucos pontos em que lhe resisti. Como fundamento, apontei o «conservadorismo» dos solos alto-algarvios e alentejanos, muito pouco transformados pelo Homem [...]" (1997: 74). É, talvez, a falta de compreensão por parte da comunidade arqueológica do funcionamento dos mapas de Capacidade de Uso dos Solos que justifica a pouca atenção dada à posição de Suzanne Daveau quanto à aplicação desta cartografia ao passado. Reconhecemos hoje que a investigadora tinha razão em alertar os arqueólogos para esta questão. O que está em causa não é tanto a discussão da permanência dos solos no tempo, mas antes o modo como os solos são avaliados nestes mapas.

\subsection{Cartas de uso e ocupação do solo de Portugal}

As cartas de Uso e Ocupação do Solo de Portugal representam os atributos biofísicos do solo e as atividades humanas que aí decorrem. A noção de "ocupação" diz respeito aos atributos biofísicos da superfície (ex. floresta), enquanto a noção de "uso" nos remete para as atividades que o Homem desenvolve nessa superfície (ex.: criação de gado). Um tipo de uso pode utilizar apenas um tipo de cobertura ou vários tipos de cobertura, assim como um tipo de cobertura pode ser alvo de um tipo de uso ou vários. Alterar o tipo de uso pode implicar uma mudança de cobertura, mas manter por muito tempo o mesmo tipo de uso também pode alterar essa cobertura (MEYER \& TURNER, 1994; MOTA et al., 2012).

Em Portugal encontramos as seguintes produções: i) COS'90 e COS'2007, escala 1/ 25 000, produzidas pelo Centro Nacional de Informação Geográfica (CNIG) em colaboração com a Associação das Empresas Produtoras de Pasta de Celulose (ACEL) (CAETANO et al., 2008; INSTITUTO GEOGRÁFICO PORTUGUÊS, 2010); ii) CLC90, CLC2000 e CLC2006, escala 1 / 100 000, produzidas no âmbito do programa CORINE (Coordination of Information on the Environment) (BOSSARD et al., 2000; CAETANO et al., 2008).

A aplicação deste tipo de cartografia ao passado é desajustada e prescindível. Ao contrário das Cartas de Capacidade de Uso, não é frequente encontrar arqueólogos que as utilizem. Os motivos que explicam a sua pouca utilidade, são, neste caso, muito claros: estão aqui representadas realidades estáticas no tempo, úteis desde uma ótica política e de planeamento, mas inadequadas para interpretar o passado.

\subsection{Cartas agrícolas e florestais de Portugal}

As Cartas Agrícolas e Florestais de Portugal representam grupos de utilização específica do solo. Publicadas pelo SROA, atestam a variedade dos usos essenciais: agrícola, florestal, agroflorestal, incultos, salinas, rios e albufeiras e povoações (RIBEIRO, 1967: 295-296).

Tal como as Cartas de Uso e Ocupação do Solo, esta cartografia não é utilizada na arqueologia pois a sua aplicação é totalmente imprópria pelos mesmos argumentos acima colocados.

\subsection{RAN e REN}

A RAN (Reserva Agrícola Nacional) constitui um tipo de representação que delimita e protege as zonas de potencial agrícola elevado e aqueloutras que, sendo sujeitas a determinadas alterações, também passaram a ter capacidade produtiva. Por seu turno, a REN (Reserva Ecológica Nacional) delimita e protege as áreas costeiras e ribeirinhas, áreas interiores, de máxima infiltração e zonas declivosas, com determinadas características ecológicas, com vista à exploração de recursos, ao equilíbrio ecológico e das estruturas biofísicas e à manutenção de valores económicos, sociais e culturais. Estas zonas encontram-se protegidas, sendo proibido construir e / ou destruir a cobertura.

Desde o ponto de vista arqueológico, não faz sentido utilizar este tipo de mapas, não só porque constituem uma imagem estática no tempo, quer 
porque são construídos com métodos pouco rigorosos.

\section{MAPA DE USOS POTENCIAIS DA TER- RA: A ALTERNATIVA FEITA POR E PARA ARQUEÓLOGOS}

É num mundo onde a tecnologia se encontra em marcada expansão que outras possibilidades metodológicas surgem e dão lugar a novas formas de indagar o passado. $\mathrm{O}$ recurso à inovação tecnológica não deve ser feito de forma obsessiva, tampouco deve impedir a utilização de metodologias tradicionais que se considerem ainda adequadas. Os recursos tecnológicos devem ser encarados como um complemento que valoriza o discurso científico e uma forma de criar novos procedimentos técnicos e aperfeiçoar outros entretanto obsoletos.

A crescente aplicação dos SIG (Sistemas de Informação Geográfica) na Arqueologia permite hoje criar com relativa facilidade cartografia ajustada às realidades das diferentes fases do passado, como é o caso dos Mapas de Usos Potenciais da Terra. Metodologicamente é uma porta que se abre repleta de inovação e potencialidades, mas que enfrenta o problema da falta de paleodados que caracterizam as diferentes zonas do mundo ao longo dos muitos anos de existência do Homem.

\subsection{Definição}

O Mapa de Usos Potenciais da Terra (MUPT) é um tipo de cartografia digital que representa os usos prováveis da terra num determinado período de tempo previamente estabelecido, permitindo ao arqueólogo refletir sobre formas de produção agrária e estratégias locacionais. O cunho histórico que distingue estes mapas da cartografia tradicional já aqui descrita, é obtido através da avaliação que o arqueólogo faz na hora de atribuir um peso aos distintos parâmetros que irão determinar o uso da terra. Para que este processo de significação histórica se realize com sucesso, é preciso, desde logo, estipular sobre que realidade estamos a trabalhar (por exemplo o Período Romano); depois, importa conhecer as dinâmicas próprias dessa realidade (por exemplo que tecnologia existia à data ou que tipo de culturas se produziam). Quanto mais conhecermos sobre a realidade agrária do período para o qual estamos a trabalhar, e quantos mais e melhores dados tivermos para compor o nosso algoritmo, mais fidedigno será o mapa gerado.

A realização de um MUPT pressupõe o abandono de noções como "limitação" e "solo", muito presentes em mapas como os de Capacidade de Uso do Solo e, como já vimos antes, inadequadas para uma avaliação credível da potencialidade da terra. O conceito de "limitação" (do solo) deve então ser substituído pela noção de "qualidades" (que otimizam o uso da terra), tal como o conceito de "solo" deve dar lugar ao de "terra", pois embora o solo seja um elemento fundamental, não é o único que colabora para a potencialidade da terra: também o clima, o relevo ou a hidrografia contribuem ativamente.

A construção de um MUPT inclui várias etapas (Fig. 1): i) recolha de dados digitais que permitam avaliar a potencialidade da terra (solo, relevo, clima, etc.) e que possam ser inseridos num SIG. Os critérios, em variedade e em número, podem alterar de mapa para mapa. Ao investigador cabe o bom senso de escolher entre aqueles critérios que tem ao dispor e avaliar a validade dos mesmos quando aplicados ao passado. Contudo, é importante compreender que alguns parâmetros são basilares e a sua omissão irá reduzir a qualidade do mapa informaticamente gerado; ii) segue-se a análise desses critérios, que deverá ser feita com recurso aos SIG. Em alguns casos é necessário proceder a uma reclassificação dos dados recolhidos em bruto. Naturalmente que estas reclassificações devem ser feitas à luz do período com o qual se está a trabalhar; iii) finalmente, deverá proceder-se à representação cartográfica do MUPT. Nesta fase, o investigador dá significado aos dados que recolheu, concedendo aos seus atributos um peso e agrupando-os em classes. Este é o momento mais sensível de todo o processo, sendo fundamental conhecer as dinâmicas do período para o qual o mapa está a ser construído. As culturas que utilizavam, a tecnologia que dispunham, o máximo de informação que nos ajude a discernir sobre o significado de áreas localizadas em zonas altas ou baixas, de maior ou menor declive, com solos mais ou menos pesados. Esta etapa conta sempre com alguma subjetividade, pois não existe uma fórmula que determine rigorosamente o valor de cada critério nos usos da terra.

\subsection{Potencialidade e problemas}

O MUPT é uma ferramenta com elevado potencial arqueológico, mas que contém, naturalmente, alguns problemas metodológicos. Neste sentido, é fundamental entender que não se trata de representar o uso real da terra, mas sim o uso provável.

Uma das características diferenciadoras destes mapas é o facto da metodologia que lhe está subjacente autorizar diferentes cenários de produção. Estes cenários devem variar de época para época, mas também podem variar dentro de uma época. Isto é possível porque os MUPT são representações contextuais, ou seja, podem ser fabricados tendo em consideração diferentes realidades económicas, agrícolas e tecnológicas: as da Idade 


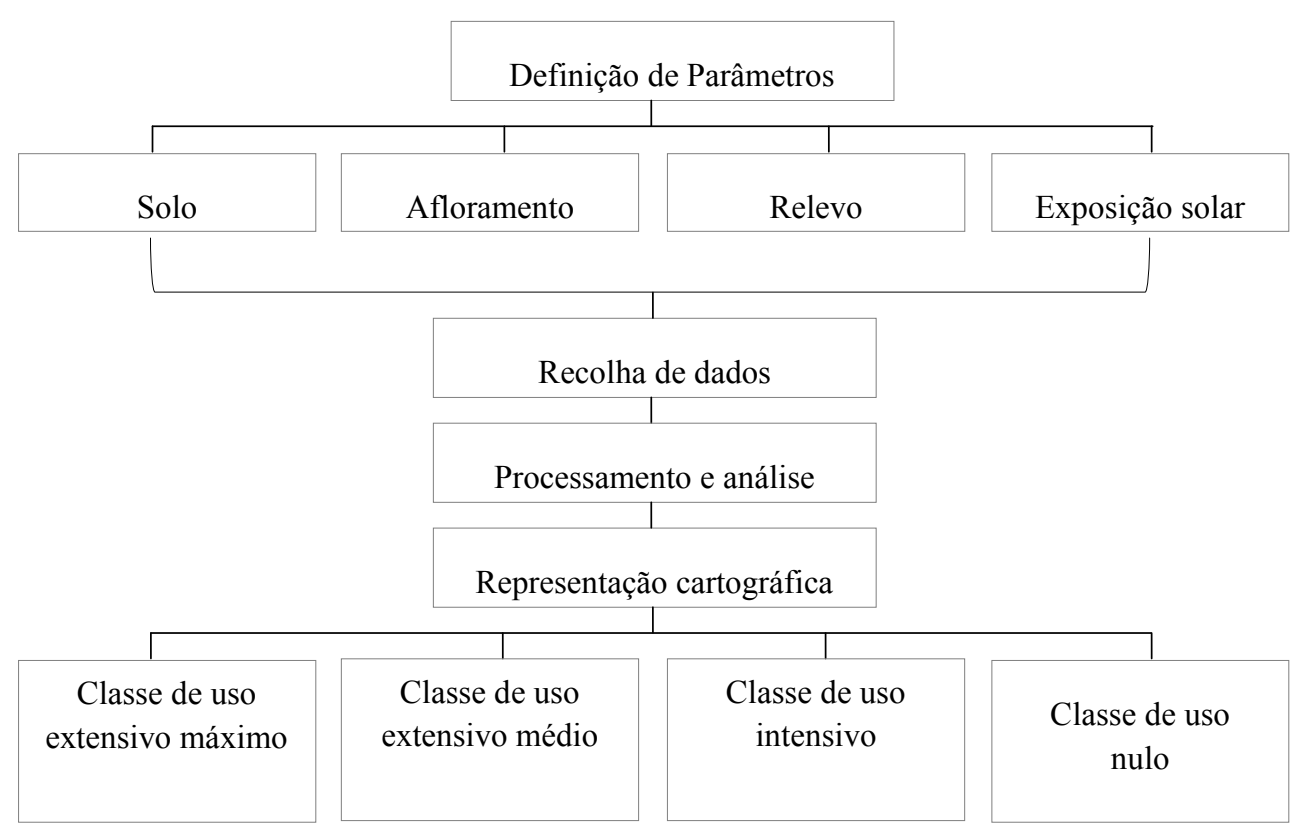

Fig. 1: Construção de um Mapa de Usos Potenciais da Terra, o caso de Idanha.

Fig. 1: The construction of a potential land use map, the case of Idanha.

do Ferro, as do Período Romano, as da Época Medieval, etc. Contudo, uma vez criado o mapa, ele passa a estar balizado cronologicamente.

As variações dos cenários produtivos dentro de uma época relacionam-se com a diversidade de classes possíveis de se adotar. A maioria dos autores que criou e aplicou esta cartografia utilizou classes de uso potencial extensivo, intensivo e nulo (PARCERO OUBIÑA, 2002; FÁBregA ÁlVAREZ et al., 2005; CURRÁS REFOJOS, 2014; LACERDA, 2017); outros autores preferiram uma classificação do tipo sequeiro, regadio e captação (OREJAS SACO DEL VALLE, 1996); Romero Perona (2015) misturou as noções de extensivo, intensivo, regadio / pasto e nulo. A escolha das classes deve, portanto, ter em consideração as circunstâncias e problemáticas de cada investigação e período.

A criação destes horizontes produtivos relaciona-se, por sua vez, com os critérios que utilizamos para construir o MUPT. Esses critérios não são fixos, nem limitados a um número. Estes mapas comportam uma metodologia muito flexível, que deixa espaço para cada um considerar diferentes parâmetros na avaliação do potencial da terra. Infelizmente não dispomos de dados suficientes que nos possibilitem reconstruir completamente o quadro natural do passado. Por esse motivo, estes mapas acabam por ter que se socorrer de dados atuais para o cálculo da potencialidade, o uso dessa informação deve por sua vez ser filtrado e consciente, acabando por ser atenuado no momento que atribuímos um peso aos critérios, convertendo-os em classes.

Outro aspeto positivo dos MUPT é o facto de comportar uma metodologia que pode ser aplicada a qualquer escala. A escala com a qual se está a trabalhar é um fator importante a considerar pois poderá influenciar a precisão do MUPT e a escolha do número e tipo de classes. Se a área de trabalho for muito reduzida, exigirá um maior grau de detalhe no que concerne a distribuição espacial dos critérios considerado. Por exemplo, quando cartografamos, por via da fotografia aérea, as manchas de afloramento rochoso, devemos ser mais minuciosos se vamos trabalhar uma área pequena e mais generalistas se vamos trabalhar uma área mais vasta. Por outro lado, trabalhando em áreas mais reduzidas, parâmetros como a temperatura ou a pluviosidade tornam-se ineficazes e pouco determinantes, ao contrário do que aconteceria numa escala alargada. De qualquer modo, aconselha-se que o investigador adote sempre uma postura pragmática e não se perca com detalhes que não terão repercussão no mapa final. No que respeita a criação das classes, áreas muito pequenas poderão não comportar a heterogeneidade suficiente para criar um sistema de classes baseado, por exemplo, no uso extensivo e intensivo da terra. Nestas situações, a utilização de classes do tipo "aptidão boa", "aptidão suficiente" e "aptidão nula”, poderá ser a única solução.

Quando trabalhamos com uma escala grande, os MUPT podem conter um potencial preditivo. Tal também é possível para áreas de trabalho pequenas desde que os investigadores disponham de trabalhos de prospeção intensiva que o possibilite, como é caso de Idanha-a-Velha (LACERDA, 2017). Importa lembrar que o MUPT, uma vez criado, se encontra condicionado cronologicamen- 
te, ou seja apenas se deve cruzar com o mapa gerado os sítios arqueológicos que são da mesma cronologia, não só para fins preditivos, como para qualquer outra análise possível.

Entre os problemas enumeráveis do MUPT, conte-se desde já o facto destas representações estarem pensadas de forma a abranger um conjunto de culturas, ignorando, desta forma, as especificidades de crescimento exigidas por cada uma. Por exemplo, quando consideramos como parâmetro a exposição solar, ao dizermos que áreas soalheiras têm maior potencialidade agrícola do que as áreas sombrias, estamos a fazer uma generalização. Embora, grosso modo, a receção de luz solar seja importante para o crescimento positivos das plantas, cada cultura tem um regime ideal próprio para a absorção da luz, algumas plantas preferem luz direta enquanto outras preferem luz indireta.

Outro aspeto que relativiza a precisão do MUPT relaciona-se com o facto das fronteiras que delimitam as classes de uso potencial serem criações muito rígidas, que descoram as zonas intermédias, de transição de uma classe para a outra. Além destas contrariedades, importa também contar com toda a margem de erro contida nos atributos dos próprios parâmetros utilizados.

\subsection{O mupt da civitas Igaeditanorum}

Em 2017, no âmbito da nossa dissertação de mestrado, foi criado um MUPT para parte do território da civitas Igaeditanorum (Idanha-a-Velha, Portugal) (Fig. 2) (LACERDA, 2017). Trata-se de um algoritmo único, desde logo porque nenhum mapa de usos potenciais da terra é igual. O MUPT de Idanha foi criado tendo em consideração as características próprias desta região, seja em termos ambientais como arqueológicos.

O modelo foi criado para uma superfície que se estende pelos campos contíguos a Igaedis capital da civitas mencionada, numa área que se cinge à CMP n. ${ }^{\circ} 270$ (1: 25 000). A escolha da área sobre a qual criámos o MUPT relaciona-se com o número de sítios arqueológicos romanos que aí se conhecem e, sobretudo, pelo facto de ter sido aí que se desenvolveu, na década de 90, um trabalho de prospeção intensiva realizado por José Ruivo, Luís Fernandes e Pedro C. Carvalho (RuIvo et al., 1991). A nossa escolha foi também condicionada pela existência ou acessibilidade de dados (por exemplo o preço da cartografia digital).

Uma das primeiras considerações a ter antes da elaboração do MUPT foram os vários aspetos

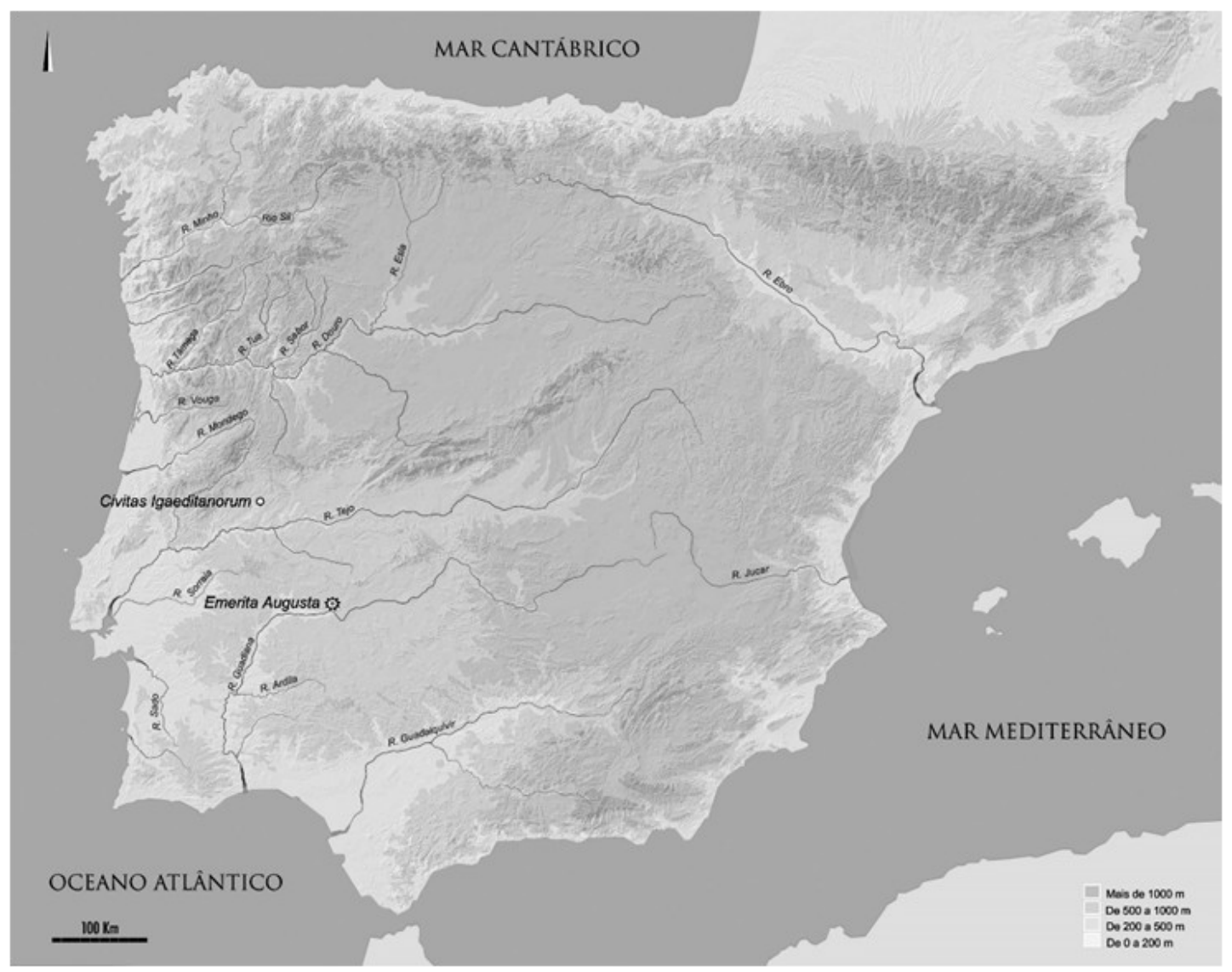

Fig. 2: Localização da civitas Igaeditanorum no contexto peninsular.

Fig. 2: Civitas Igaeditanorum localization in the peninsular context. 
da produção e tecnologia agrária do mundo romano, que conhecemos através dos dados arqueológicos, mas sobretudo das fontes, onde se destacam autores como Catão (De agri Cultura, séc. II a.C.), Varrão (De re rustica, séc. I a.C.), Columela (De re rustica, séc. I d.C.) ou Paládio (Opus agriculturae, séc. V d.C.).

No diz respeito à produção agrícola Romana, destacam-se os cereais (trigo, cevada, aveia, milhomiúdo), a vinha e a oliveira. Além destas, refira-se as hortaliças, os legumes, as ervas aromáticas, as árvores de fruto e para a pastagem, o feno, o trevo e o tremoço. Aos produtos resultantes da produção agrícola somavam-se os da criação de gado, esta prática, muito silenciosa no registo arqueológico, deverá ter sido recorrente já que exigia menos mão -de-obra e manutenção relativamente à agricultura e não estava tão dependente de fatores naturais. Quanto à tecnologia, as alfaias agrícolas romanas incluíam a enxada, o sacho, o alvião, o ancinho, a pá, a grade e o arado, além dos instrumentos que serviam para manusear por exemplo a erva e aqueloutros utilizados na ceifa e na eira (ALARCÃO, 1997: 136-1148; 2004:29-40).

Os parâmetros considerados para a elaboração do MUPT foram obtidos a partir de várias fontes: consulta de bibliografia específica, análise de fotografia aérea, leitura de cartografia temática e a elaboração de cálculos com recurso às ferramentas dos SIG. São eles:
A. O solo, corpo dinâmico, natural e não consolidado, que constitui a base de toda a atividade agrícola. Como vimos anteriormente, existem diferentes tipos de solo, sendo cada um composto por diferentes variáveis físicas, químicas e biológicas, que por sua vez são determinantes para o tipo de utilização que deles se faz. Na Carta de Solos 270 / 1: 25 000 (Fig. 3) podemos observar os diferentes tipos de solo que compõem a nossa área de estudo, com uma predominância muito significativa de solos esqueléticos, de pouca profundidade.

B. O afloramento rochoso foi identificado por via da fotointerpretação e vectorização da fotografia aérea do Bing Maps (por meio do QGIS 2.14 Essen). Verifica-se, no mapa da figura 4, a existência de duas manchas de afloramentos rochosos de granitos ou quartzodioritos, sendo a mais predominante aquela que se encontra situada ao centro e a norte.

C. O relevo encontra-se representado no Modelo Digital do Terreno (MDT) visível no raster da figura 4. Este critério foi gerado em ambiente SIG, mediante um cálculo de interpolação que teve por base as curvas de nível da CMP 270 à escala 1: 25000. Verificamos

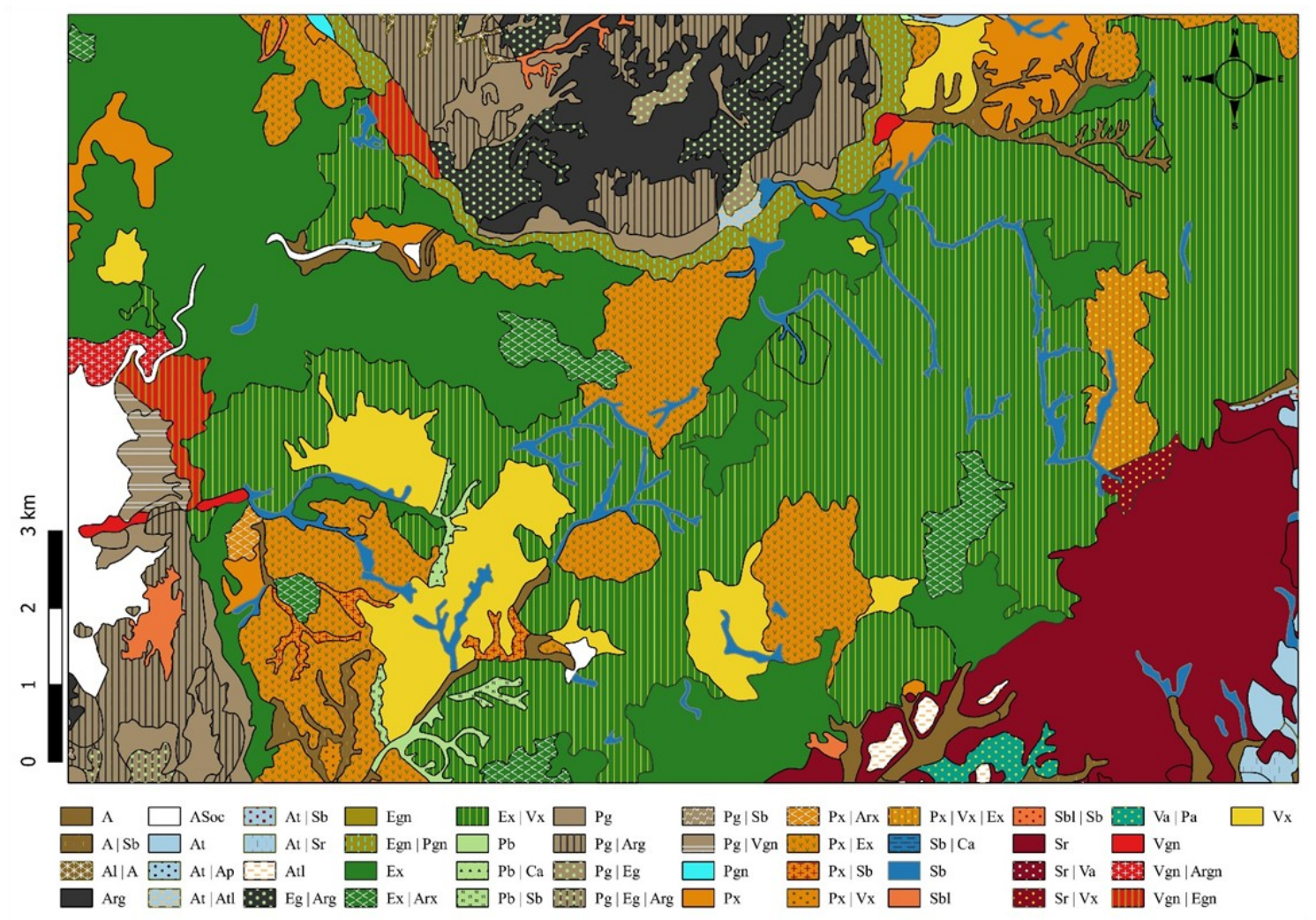

Fig. 3: Carta de Solos n. ${ }^{\circ}$ 270 / 1: 25000.

Fig. 3: Soil Map No, 270 / 1: 25000. 
como a região estudada apresenta um relevo bastante uniforme, com valores que variam entre os 570 (na serra da Murracha) e 250 metros (ao longo do Ponsul). É importante entender que a variação da morfologia, do declive e da altitude, tem repercussões diretas na incidência da luz solar e dos ventos (determinando a ação da erosão), na existência de infiltrações, escorrimentos de águas da chuva, acumulações ou arrastamentos de detritos, podendo também interferir com a profundidade dos solos (REED et al., 2000: 710). Todas estas alternâncias podem, em grande medida, condicionar a utilização da terra para fins agrícola, dependendo da disponibilidade tecnológica que existe no período que se está a estudar. Ao observarmos o mapa de declives da figura 5 , calculado em ambiente SIG a partir do MDT, verificamos como, grosso modo, dispomos de uma área com declives suaves (entre 0 e $15 \%$ ) e, portanto, com potencial agrícola. As áreas mais

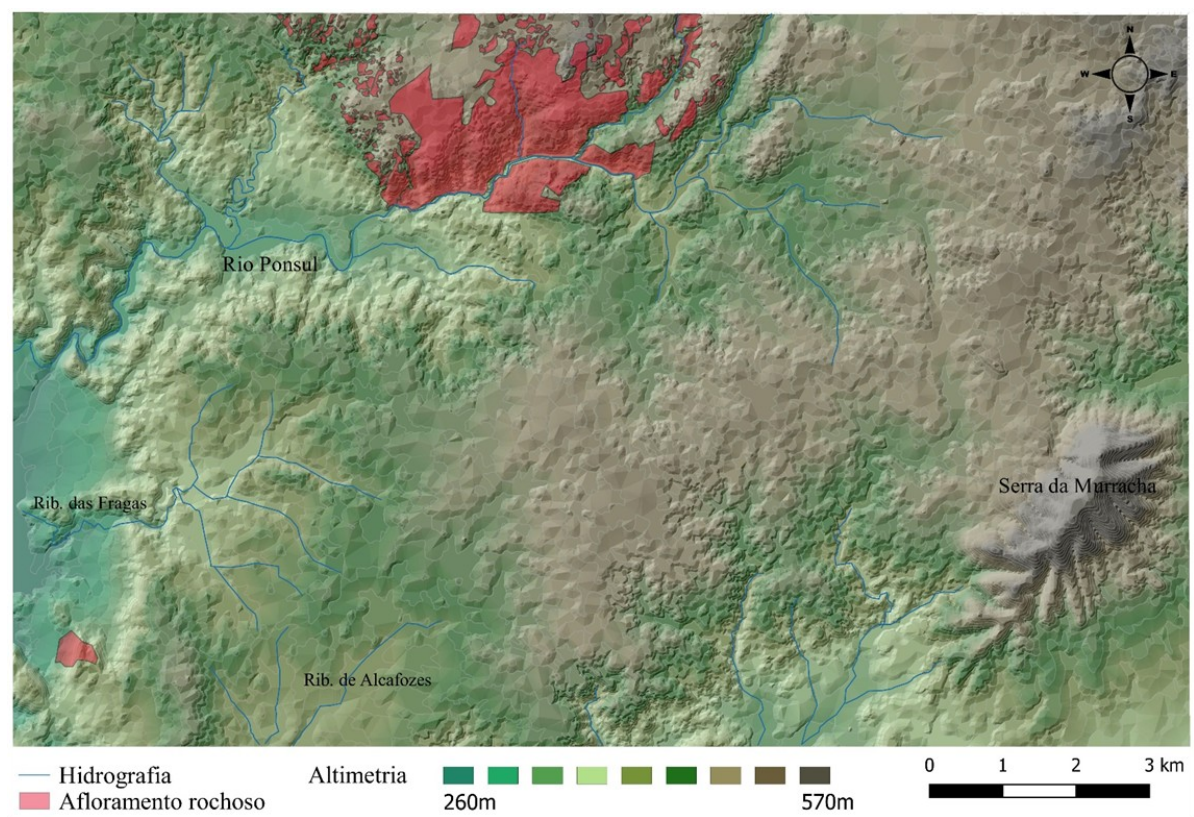

Fig. 4: Modelo digital do terreno e áreas de afloramento rochoso. Fig. 4: Digital terrain model and rocky outcrop areas.

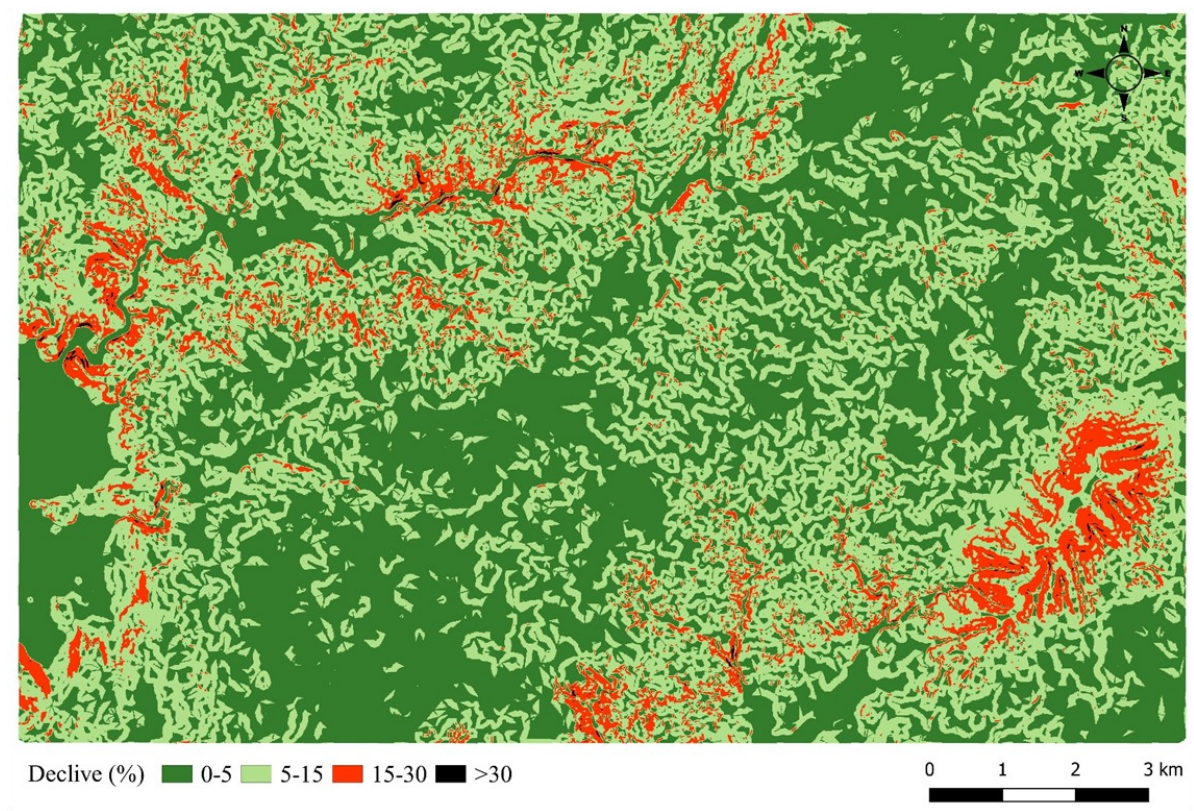

Fig. 5: Mapa de declives.

Fig. 5: Slope map. 
Usos potenciais da terra na antiguidade como alternativa às representações cartográficas dos solos existentes em Portugal. O caso da civitas Igaeditanorum (Idanha-a-Velha, Portugal)

D. A exposição solar da região (Fig. 6) foi calculada, também ela, em ambiente SIG. A partir deste mapa podemos observar quais as áreas que se encontram expostas à luz solar e, portanto, com um maior potencial agrícola, e aquelas que estão em zonas de sombra, menos aptas. As áreas planas foram consideradas por nós positivamente, uma vez que se situam em zonas abertas, ou seja, não se encontram rodeadas de elevações que impeçam a receção de luz.

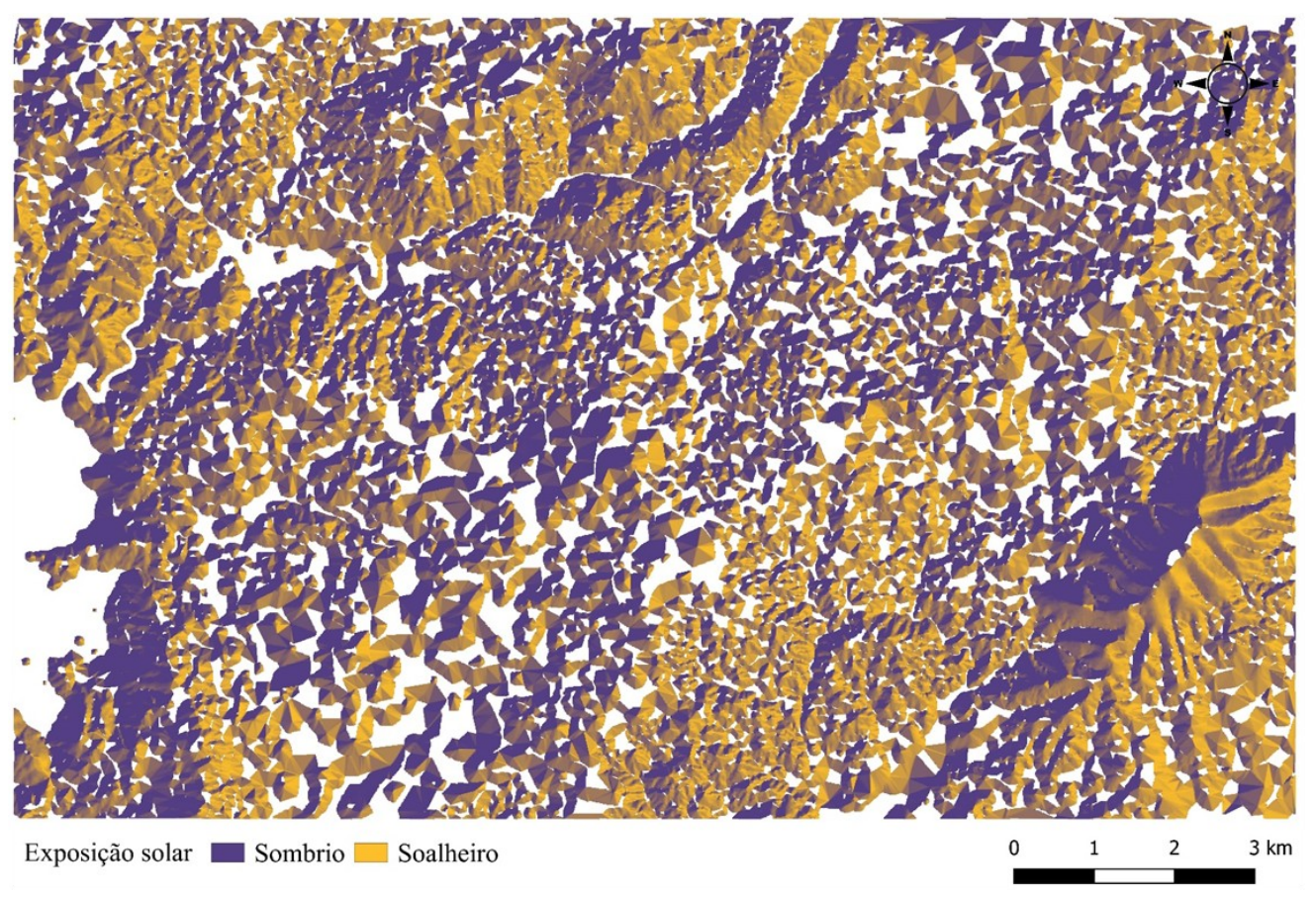

Fig. 6: Mapa de exposição solar.

Fig. 6: Solar exposure map.

Como já antes referimos, a inexistência de uma fórmula que nos permita avaliar com exatidão o peso de cada parâmetro nos usos da terra, dá azo à consideração de diferentes critérios e formas de os classificar. Por outro lado, a escolha dos mesmo encontra-se relacionada com a existência de dados e a acessibilidade aos mesmos. Ao mencionado acresce o facto de trabalharmos uma área reduzida, o que faz com que critérios como a temperatura, o regime hídrico ou o regime de geadas, não tenham leitura devido à homogeneidade do fenómeno em toda a área.

Por seu turno, a seleção das variáveis de cada critério que se inserem numa ou noutra classe de uso da terra é um processo difícil e com alguma margem de erro. No caso do MUPT de Idanha as escolhas feitas podem resumir-se na seguinte tabela:

Tab. 1: Classes de uso potencial da terra para o território de Idanha. Tab. 1: Land evaluation clases for the territory of Idanha.

\begin{tabular}{|c|c|c|c|c|}
\hline $\begin{array}{c}\text { Parâmetros / } \\
\text { Classes }\end{array}$ & $\begin{array}{c}\text { Potencial extensivo } \\
\text { máximo }\end{array}$ & $\begin{array}{c}\text { Potencial extensivo } \\
\text { médio }\end{array}$ & Potencial intensivo & Potencial nulo \\
\hline Declive & $0-15 \%$ & $15-30 \%$ & $0-15 \%$ & $>30 \%$ \\
\hline $\begin{array}{c}\text { Exposição } \\
\text { solar }\end{array}$ & solarengo & sombrio & solarengo & - \\
\hline Solos & $\begin{array}{c}\text { solos podzolizados; } \\
\text { solos argiluviados }\end{array}$ & $\begin{array}{c}\text { solos incipientes; solos } \\
\text { litólicos }\end{array}$ & $\begin{array}{c}\text { solos incipientes da } \\
\text { subordem aluviossolos; } \\
\text { solos incipientes da } \\
\text { subordem coluviossolos }\end{array}$ & $\begin{array}{c}\text { zonas de aflora- } \\
\text { mento rochoso; } \\
\text { área social; solos } \\
\text { hidromórficos }\end{array}$ \\
\hline
\end{tabular}


A representação cartográfica desta seleção culminou no MUPT de Idanha romana (Fig. 7). O MUPT de Idanha consiste numa superfície categorizada em quatro classes de uso potencial da terra: uso potencial extensivo máximo, uso potencial extensivo médio, uso potencial intensivo e uso potencial nulo. Na nossa consideração, as noções de uso extensivo (onde o uso máximo pressupõe menos dificuldades produtivas que o uso médio), intensivo e nulo são ideais por serem suficientemente abrangentes e representativas. Assim, a agricultura de tipo extensivo está relacionada com solos ligeiros, drenados e pouco profundos, recorrendo geralmente a tecnologia pouco elaborada; enquanto a agricultura de tipo intensivo remete para solos pesados, nutridos e alagados, exigindo um maior conhecimento da terra e outro tipo de tecnologia.

Para chegarmos ao mapa final foi necessário recorrer a uma funcionalidade complexa dos SIG, baseada em operações de álgebra de mapas. Este processo matemático foi explorado por Dana Tomlin (1990) e parte do pressuposto que a cada célula de um mapa se pode associar um valor quantitativo ou qualitativo. Com base nesses valores, é depois possível executar várias operações (zonais, pontuais ou de vizinhança).

Nesta fase final, para obtermos o MUPT existem duas etapas fundamentais. A primeira fase relaciona-se com os requisitos exigidos para a execução da operação de álgebra de mapas e passa pela conversão das variáveis dos critérios considerados em valores numéricos. Cada um desses valo- res numéricos representam nada mais que as classes criadas. Por outras palavras, nesta fase atribuímos a cada uma das 4 classes de uso potencial criadas um número: a classe de potencial nulo é representada pelo número 0 ; a classe de potencial extensivo médio pelo número 1 ; a classe de potencial extensivo máximo pelo número 2 ; e a classe de potencial intensivo pelo número 3. Depois, fizemos corresponder a cada uma das células dos mapas dos critérios um valor, de acordo com a classe em que essa célula se insere. Por exemplo, as células do mapa do critério solo representam a diversidade de solos existentes na nossa área de trabalho e esses solos já foram devidamente avaliados na tabela 1, sendo atribuídos a uma classe de uso potencial. Nesta fase, o que fizemos foi dizer ao software SIG que aquelas células que correspondem, por exemplo, a solos do tipo incipiente da subordem aluviossolos e a solos incipientes da subordem coluviossolos correspondem ao valor número 3 , valor esse que, por sua vez, corresponde à classe de uso potencial intensiva.

Uma vez concluída esta etapa de conversão dos dados em valores numéricos, executou-se a operação de álgebra de mapas e gerou-se assim o mapa final dos usos potenciais da terra de Idanha. Esta operação gera automaticamente um mapa em formato raster que optamos por converter para formato vetorial, de forma a facilitar a leitura do mesmo. Finalmente, a cada uma das manchas representativas de uma ou outra classe, foram atribuídas uma cor e uma textura, como podemos verificar na legenda da figura 7 .

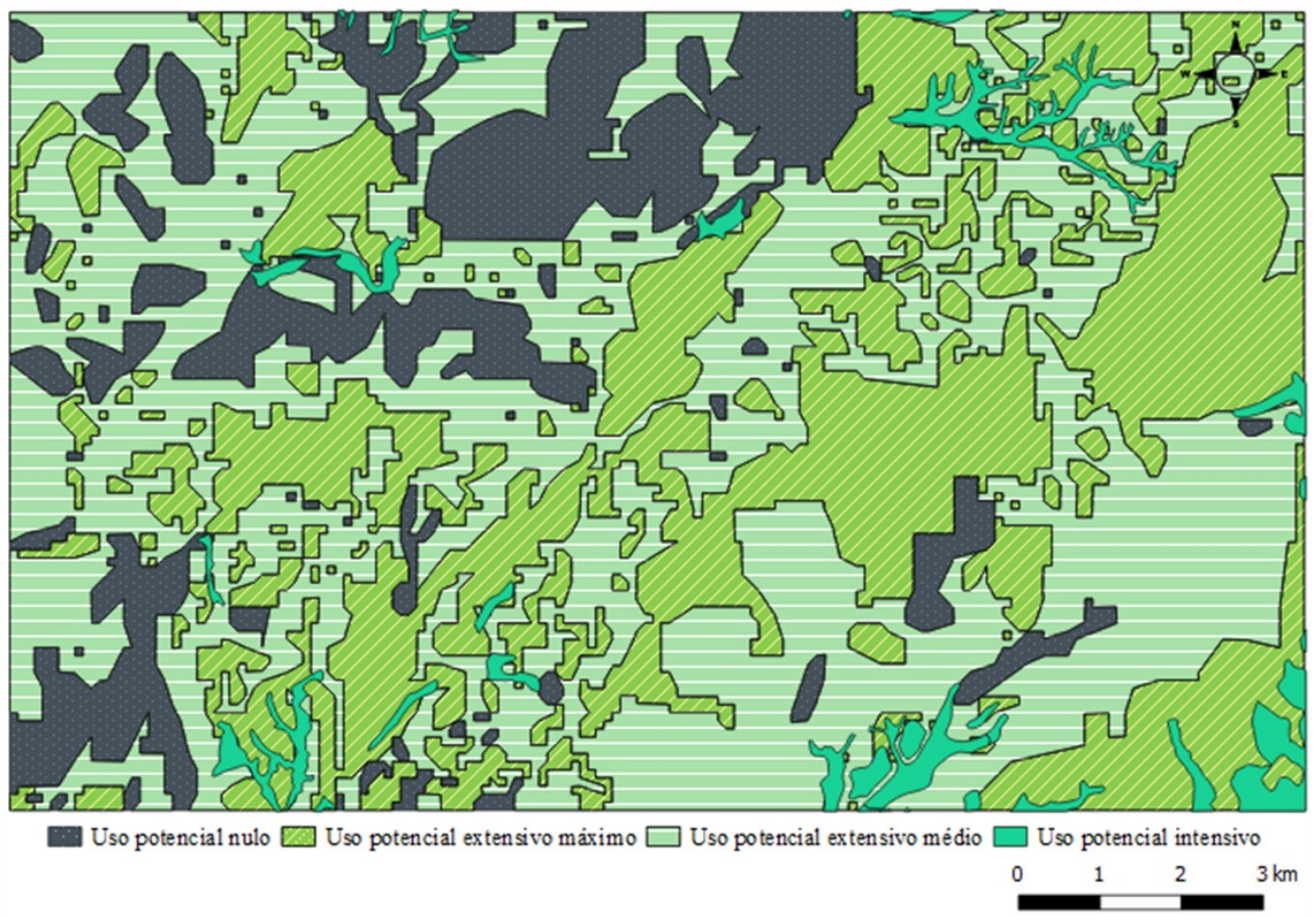

Fig. 7: Mapa de Usos Potenciais da Terra de Idanha.

Fig. 7: Land evaluation map of Idanha. 


\section{OBSERVAÇÕES FINAIS}

O facto dos MUPT representarem um conjunto de classes que avaliam a terra tendo por base parâmetros pensados, desde o início, para serem aplicados ao passado, faz destas representações a nossa melhor opção. Os problemas que comportam estes mapas são, em contrapartida, pouco significativos ao lado dos problemas implicados no uso da cartografia tradicional de solos, nomeadamente nas Cartas de Capacidade de Uso do Solo. A grande diferença entre esta cartografia e os mapas tradicionais é que no MUPT os dados são filtrados e o sistema de classificação das unidades é determinado pelo objetivo previamente estabelecido pelo seu criador e, portanto, adaptado à realidade do período com o qual se está a trabalhar.

A Arqueologia é a mediadora entre o passado e o presente e ao seu alcance está apenas uma realidade interpretada. Tal como toda a Arqueologia, também o MUPT comporta essa relatividade: através dele podemos tentar reconstruir o passado, mas nunca recuperá-lo. Argumentar que a aplicação desta cartografia ao passado não tem viabilidade porque comporta erros, é, portanto, paradoxal.

Neste artigo a nossa perspetiva foi essencialmente metodológica, visando mostrar, a partir do caso de Idanha, em que consiste esta cartografia, em que medida ela deve ser considerada cartografia arqueológica, qual a sua utilidade, quais os seus problemas e como pode ser construída. A etapa do cruzamento de dados - usos da terra e povoamento rural romano, é o principal objetivo deste longo processo aqui relatado, porém a complexidade dessa análise requer uma abordagem singular (LACERDA et al. NO PRELO). Só deste modo poderemos atestar a viabilidade do mapa gerado e compreender o modo como funcionou, neste caso, o povoamento rural do entorno da civitas Igaeditanorum em função da terra.

Ao observarmos o MUPT de Idanha percebemos aspetos genéricos caracterizadores desta região no Período Romano: o predomínio de áreas de uso potencial extensivo relativamente ao uso potencial intensivo e a existência de zonas pontuais relativamente amplas sem qualquer tipo de aptidão agrícola.

Ainda que a Carta de Capacidade de Uso do Solo (25 A; 1: 50 000) reduza a zona de Idanha a uma classe não suscetível de utilização agrícola e a paisagem que hoje encontramos seja essencialmente voltada para a pastorícia, tal não significa que tenha sido sempre assim. A "campanha do trigo" dos anos 30 (NUNES, 2002-2004: 95), tal como a informação que nos é transmitida pelos agricultores locais, descreve-nos um passado que não se coaduna com a ideia de inaptidão. Essa paisagem essencialmente cerealífera deverá, por seu turno, recuar ao Período Romano, como nos mostra o mapa de usos potenciais gerado.
Como tal, com o Mapa de Usos Potenciais passa a ser possível avaliar as paisagens agrárias de uma forma mais fidedigna, já que a subjetivação que lhe está subjacente é construída por arqueólogos que consideram as múltiplas variáveis inerentes às diversas fases da história do Homem. Entre essas variáveis, conta-se desde logo o modo como foi entendido o espaço agrícola, o que era considerado como um bom, um mau ou um inadequado espaço agrícola, o que se cultivava e com que meios. A partir daqui, é possível ao arqueólogo entender qual o papel destes espaços agrários na paisagem e de que modo eles se relacionam com quem a habita ou como determinam decisões de carácter político e / ou administrativo.

\section{AGRADECIMENTOS}

Agradecemos ao Brais Currás Refojos o apoio prestado para a produção deste MUPT. A Marcos Osório e Pedro C. Carvalho pela disponibilidade, leituras e conselhos. A José Luís Madeira a elaboração do mapa da Península Ibérica. E à DGADR agradecemos a cedência e permissão para publicar a Carta de Solos apresentada. Este trabalho inscreve -se no quadro do Projeto de Investigação Plurianual (DGPC: 2016-2019) intitulado "IGAEDIS. Da civitas Igaeditanorum à Egitânia. A construção e evolução da cidade e a definição dos seus territórios da Época Romana até à doação dos Templários (séculos I a XII)", executado no âmbito de um protocolo celebrado entre o Município de Idanha-a-Nova, a Universidade de Coimbra (FLUC) e a Universidade Nova de Lisboa (FCSH)

\section{BIBLIOGRAFIA}

Agroconsultores \& Cobra. 1991. Carta de Solos, Carta de Uso Actual da Terra e Carta da Aptidão da Terra do Noroeste de Portugal, Escala 1: 100000. Vila Real, Universidade de Trás-os-Montes e Alto Douro.

Agroconsultores \& Geometral. 1995. Carta de Solos e Carta de Aptidão da Terra de Entre Douro e Minho, Escala 1: 100 000. Braga, Direcção Regional da Agricultura e Entre Douro e Minho.

Agroconsultores \& Geometral. 1999. Carta de Solos e Carta de Aptidão da Terra de Entre Douro e Minho, Escala 1: 25 000. Braga, Direcção Regional da Agricultura e Entre Douro e Minho.

AlARCÃO, JORGE DE. 1997. A tecnologia agrária romana. In: Portugal Romano: a exploração dos recursos naturais. Lisboa, Museu Nacional de Arqueologia: 136-148.

AlARCÃO, JORGE DE. 2004. Introdução ao estudo da tecnologia romana. Coimbra, Instituto de Arqueologia da Faculdade de Letras da Universidade de Coimbra: 29-39.

Caetano, Mário; Pereira, Maria; Carrão, Hugo; ARAÚJO, ANTÓNIO, NUNES, ANTÓNIO \& NUNES, VASCO. 2008. Cartografia temática de ocupação / uso do solo do Instituto Geográfico Português. Mapping - Revista Internacional de Ciencias de la Tierra, n. ${ }^{\circ} 126,78-87$.

CARdoso, José V. J. DE CARvalho. 1965. Os solos de 
Portugal. Sua classificação, caracterização e génese. 1 - A sul do rio Tejo. Lisboa, Secretaria de Estado da Agricultura, Direcção Geral dos Serviços Agrícolas.

Cardoso, José V. J. De Carvalho. 1974. A classificação dos solos de Portugal. Nova Versão. Bol. de solos do SROA., n. ${ }^{\circ}$ 17: 14-46.

Currás Refojos, Brais X. 2014. Mapa de usos potenciales de la tierra de Galicia. Una perspectiva arqueológica. Trabajos de Prehistoria, 71, n. ${ }^{\circ}$ 1: 23-41. http://tp.revistas.csic.es/index.php/tp/article/ view/663

BOSSARD, M; FERANEC, J. \& OTAHEL, J. 2000. CORINE land cover technical guide - Addendum 2000. Technical report No 40. Copenhagen, European Environment Agency. https://www.eea.europa.eu/ publications/tech40add

FÁbrega Álvarez, Pastor; Parcero Oubiña, César \& MÉndez SANTIAGo, PAUla. 2005. Alén dos castros de O Neixón: análise dixital dunha paisaxe arqueolóxica. In: Ayán Vila, Xurxo M. (coord.): Os castros do Neixón: recuperación dendê a Arqueoloxía dun espácio social e patrimonial. Noia, Toxosoutos: 247-287. http://hdl.handle.net/10261/52263

FAO (Food and Agriculture Organization of the United Nations). 2007. Land evaluation.

Towards a revised framework. Land and water discussion paper 6. Roma, FAO. http://www.fao.org/3/aa1080e.pdf

FAO (Food and Agriculture Organization of the United Nations) \& UNESCO (United Nations Educational, Scientific and Cultural Organization). 1997. Soil Map of the World: revised legend with corrections and updates. World Soil Resources Report 60. Wageningen, ISRIC. http://www.fao.org/fileadmin/ user_upload/soils/docs/isricu_i9264_001.pdf

GonçALVES, Victor S. 1997. Suzanne Daveau e a arqueologia: tempo e espaço. Finisterra, XXXII, 63: 7180. http://revistas.rcaap.pt/finisterra/article/ viewFile/1785/1471

Instituto Geográfico Português. 2010. Memória descritiva da Carta de Uso e Ocupação do Solo de Portugal Continental para 2007 (COS2007). http://www.dgterritorio.pt

LACERDA, SOFIA. 2017. Povoamento rural romano e usos potenciais da terra em torno da capital da civitas Igaeditanorum (Idanha-a-Velha, Portugal). Dissertação de Mestrado apresentada à Faculdade de Letras da Universidade de Coimbra.

Lacerda, Sofia; Osório, Marcos; Carvalho, Pedro C. No prelo. Contributo para o estudo do povoamento rural de Igaedis (civitas Igaeditanorum) através de um mapa de usos potenciais da terra (MUPT).

MARQUES, F. SACRAMENTO. 1958. Legenda provisória dos Solos e afloramentos rochosos cartografados a Sul do Rio Tejo. Caracterização geral dos Solos. Lisboa, SROA.
Mota, Andreia; Bento-GonÇALVEs, ANTÓNIO \& Vieira, ANTÓNIO. 2012. Uso e ocupação do solo em Portugal - Aspectos metodológicos para atualização de cartografia temática. AURORA geography jornal, n. ${ }^{\circ}$ 4: 101-113. http://repositorium.sdum.uminho.pt/ handle/1822/37379

Nunes, AdÉLIA. 2002-2004. Uso do solo em Portugal continental: aspectos gerais da sua evolução. Cadernos de Geografia, n. ${ }^{\circ}$ 21/23, 91-103.

Orejas Saco Del Valle, Almudena. 1996. Estructura social y território. El impacto romano en la cuenca noroccidental del Duero. Madrid, Anejos de Archivo Español de Arqueología, XV, CSIC.

PARCERO OUBIÑA, CÉSAR. 2002. La construcción del paisaje social en la Edad del Hierro del Noroeste ibérico. Ortegalia 01, Monografías de Arqueología, Historia y Patrimonio. Ortigueira, Fundación Ortegalia. http://hdl.handle.net/10261/14882

PISSARRA, J. BAILIM. 1980-1981. O papel da litologia na cartografia dos solos de Portugal. Boletim da Sociedade Geológica de Portugal, vol. XXII: 261265.

ReED, Stewart; BAILEy, NATHAN \& OGHNEKOME, ONOKPISE. 2000. Soil science for archaeologists. Editado por Michael Russo e Virginia Horak. Florida Agricultural and Mechanical University and Southeast Archeological Center, National Park Service.

Ribeiro, Orlando. 1967. Mapa da utilização do solo em Portugal. Finisterra, II, 4: 295-296.

Romero Perona, DAmiÁn. 2015. Territorio y formaciones sociales en la zona astur-lusitana del Duero. Dissertação de Doutoramento apresentada à Universidade de Valência. http://roderic.uv.es/ handle/10550/50843

Ruivo, José; Fernandes, Luís \& CARvalho, Pedro C. 1991. Um ensaio de prospecção sistemática na área de Idanha-a-Velha. Coimbra, Instituto de Arqueologia da Faculdade de Letras da Universidade de Coimbra (Seminário de Arqueologia: trabalho académico policopiado).

S.P.C.S. (Sociedade Portuguesa da Ciência do Solo). 2004. Bases para a revisão e actualização da classificação dos solos em Portugal. Lisboa, Protocolo entre o Instituto de Desenvolvimento Rural e Hidráulica e a Sociedade Portuguesa da Ciência do Solo. https:// parceriaptsolo.dgadr.gov.pt/images/ Relatorio_protoc_IDRHA-SPCS_FIN.pdf

TOMLIN, DANA. 1990. Geographic Information Systems and Cartographic Modeling. United States, Prentice Hall. 